\title{
In Vitro Assay and Dissolution Study of Diclofenac Sodium Tablets Marketed In Port Harcourt, South - South Nigeria
}

\author{
Ordu J I (Corresponding author) \\ Department of Pharmaceutics / Pharmaceutical Technology, \\ Faculty of Pharmaceutical Sciences, University of Port Harcourt, Nigeria \\ Email: ordujohnik@yahoo.com \\ Ordu J I, Ifeme Chijioke \\ Department of Pharmaceutics / Pharmaceutical Technology, \\ Faculty of Pharmaceutical Sciences, University of Port Harcourt, Nigeria
}

\begin{abstract}
The aim of this study is to determine the potency of Diclofenac sodium tablet available in Port Harcourt metropolis, south-south Nigeria. Diclofenac Sodium is a potent Non-Steroidal AntiInflammatory Drug (NSAID) commonly used as an Over the Counter (OTC) drug. Potency determination was performed to evaluate and authenticate whether the marketed samples complies with the declared specification. In vitro dissolution study was, performed to verify the potency of the drug and its relative bioavailability. Hardness was checked to verify whether it interferes with the dissolution, which might ultimately affect the drug bioavailability. In this present study, a simple, cost effective, and spectrophotometric method for the potency determination of marketed diclofenac sodium tablets is used. Six samples were randomly collected from the market and coded as A, B, C, D, E and F, and the potency determined are $80 \%, 98.7 \%, 126.9 \%, 99.6 \%, 109.2 \%$ and $91.4 \%$ respectively. Hardness and in vitro dissolution of the six brands of diclofenac sodium tablet were studied and reported. After $1 \mathrm{~h}$ dissolution release of samples A, B, C, D, E, and F are 135\%, 30\%, 70\%, 122\%, $38 \%$, and $40 \%$ respectively. The results obtained from the study signified, that not all the samples analyzed complied with the BP and USP standards or requirements.
\end{abstract}

Key words: Diclofenac Sodium, In vitro assay, Dissolution, Potency, Relative bioavailabiity

DOI: $10.7176 / J S T R / 7-02-06$

\section{Introduction}

Diclofenac is a nonsteroidal anti-inflammatory drug (NSAID) with antipyretic and analgesic actions effective in the management of pain, inflammation and stiffness caused by many conditions such as osteoarthritis, rheumatoid arthritis, abdominal cramps associated with menstruation and ankylosing spondylitis [1].

It exists in two salt forms, diclofenac sodium and diclofenac potassium and each salt contains the same amount of diclofenac base. The difference between the two forms being that diclofenac potassium is slightly more soluble in water, therefore readily absorbed and has faster onset of analgesic activity than diclofenac sodium [2].

Diclofenac is a benzene acetic acid derivative and a non- selective reversible and competitive inhibitor of cyclooxygenase (COX) which blocks the conversion of arachidonic acid into prostaglandin precursors leading to an inhibition of the formation of prostaglandins a factor involved in inflammation and fever [3].

The diclofenac sodium tablets can be formulated into various forms including, the conventional and prolonged/slow/sustained release tablets. Clinical responses to these drug products from different manufacturers have been observed and this may be because of some differences in excipient contents, formulation process, packaging, storage condition, and level of in-process quality control observed by

54 I P a g e

www.iiste.org 
the manufacturers from the point of raw material purchase to when the tablets are packaged and distributed.

Many generic versions of diclofenac tablets by different producers and from different countries are sold in the country (Nigeria) today hence there is a need to ascertain their compliance to the pharmacopoeia standard. However, for a tablet to be considered satisfactory it is not enough for it to be elegant and firm to withstand handling, it must have to satisfy certain approved tests/ procedures as contained in the reference standard some of which include, weight variability, hardness, friability, dissolution and disintegration time often classed as official and unofficial tests.

In relation to the mehanism of action of diclofenac sodium, two COX iso enzymes such as COX-1 and COX-2. COX-1, have been identified and these have been expressed constitutively, synthesized continuously and is present in all tissues and cell types. The COX-1 is important for the production of prostaglandins and for homeostatic maintenance, such as platelet aggregation, the regulation of blood flow in the kidney and stomach, and the regulation of gastric acid secretion. Inhibition of COX-1 activity is a major contributor to NSAID GI toxicity. COX -2 is considered an inducible iso - enzyme, although there are some constitutive expression in the kidney, brain, bone, female reproductive system , neoplasms, and GI tract. The COX-2 iso enzyme plays an important role in pain and inflammatory process [4].

The NSAIDS inhibits prostaglandin synthesis by causing blockade of the transiently expressed prostaglandin endoperoxide synthase-2(PGES-2) also known as cyclogenase-2 (COX-2) and perceived to exhibit bacteriostatic activity by inhibiting bacterial DNA synthesis [4]. Diclofenac inhibits COX-2 with 20 time's greater potency than the constitutively expressed isoenzyme COX-1 and therefore has somewhat lower incidence of gastrointestinal complaints than observed with aspirin, which inhibits COX-1 to a greater extent.

\section{Pharmacokinetics Properties of Dilcofenac Sodium}<smiles>NOC(=O)Cc1ccccc1Nc1c(Cl)cccc1Cl</smiles>

Fig 1: Chemical structure of diclofenac sodium

Diclofenac sodium has an acidity constant of 4 and a partition coefficient of 13.4. The structural elements include a phenylacetic acid group, a secondary amino group, and a phenyl ring containing chlorine atom which cause maximum twisting of the ring [2].

The half life $\left(\mathrm{T}^{1 / 2}\right)$ in plasma varies from 1-3 hours [5] with mean peak plasma levels of approximately $0.5 \mathrm{ug} / \mathrm{ml}$ and $1.0 \mathrm{ug} / \mathrm{ml}$ occurring after about two hours following single doses of $25 \mathrm{mg}$ and $50 \mathrm{mg}$ of enteric-coated tablets respectively. Animal studies have shown that the highest concentrations of diclofenac are found in bile, liver and kidneys followed by blood, heart and lungs.

Diclofenac like all NSAIDs is $\geq 99.5 \%$ bound to human serum proteins, specifically albumin. It accumulates in synovial fluid after oral administration, which may explain the duration of therapeutic effect that is considerably longer than the plasma half-life [5].

It is, rapidly and effectively absorbed after conventional oral, rectal, or intramuscular administration where peak plasma concentrations are attained after 10 to 30 minutes but with enteric-coated formulation peak concentrations are reached after 1.5 to 2.5 hours, and this is delayed by food to 2.5 to 12 hours.

Diclofenac undergoes significant first- pass metabolism and only $60 \%$ of the drug reaches systemic circulation unchanged following oral administration. It is eliminated mainly by hepatic metabolism and the principal metabolite in human is 4-hydroxydiclofenac, which possesses negligible antiinflammatory activity compared with the parent drug, the amount excreted in urine accounts for 20 to $30 \%$ of the dose and that in bile, 10 to $20 \%$.

Administration of diclofenac may be associated with such common adverse effects as, headache, dizziness, dyspepsia, abdominal pain, anorexia, rash while the rare type include, hypersensitivity,

55 | P a g e

www.iiste.org 
anaphylactic reactions(including hypotension and shock), somnolence, asthma and gastrointestinal haemomorrhage [6].

Contraindications of diclofenac includes, hypersensitivity, history of allergic reactions while concomitant use, with other NSAIDs as aspirin, may activate stomach and/or duodenal ulceration or gastrointestinal bleeding, inflammatory bowel disease such as Crohn's disease or ulcerative colitis hence must be used with caution during third trimester pregnancy and in patients with pre-existing hepatic porphyria, as it may trigger attacks [7].

Drug interactions of diclofenac exists therefore, concomitant use of diclofenac SR with systemic NSAIDS including COX-2 selective inhibitors should be avoided reason being, lack of evidence showing synergistic benefits rather there could be potentiation of possible adverse effects.

\section{Tablets}

According to the Indian Pharmacopoeia, pharmaceutical tablets are solid, flat or biconvex dishes, unit dosage form, prepared by compressing a drug or a mixture of drugs, with or without diluents. They vary in shape and differ greatly in size and weight, depending on amount of medicinal substances and the intended mode of administration [8].

Tablet is associated with such properties as, accurate dosage of medicament, uniformity in weight, appearance and diameter, having the strength to withstand the rigors of mechanical shocks during production, packaging, shipping and dispensing, ability to release the medicinal agents in the body in a predictable and reproducible manner, elegant product and acceptable in size and shape [9].

The standard uncoated tablets are, made by either direct compression, wet granulation, dry granulation and may be used for local action in GIT/systemic system in addition to other medicinal agents.

Sustained release formulations also known as prolonged release formulations or time release includes, any drug delivery system that achieves slow release of drug over an extended period. Most sustained release formulations are, designed so that the administration of a single unit dosage provides the immediate release of an amount of drug that promptly produces the desired therapeutic effect and gradually and continuously release the additional amount of drug to maintain its level of effect over an extended period usually eight to twelve hours [10].

Clinical advantages of such formulation includes reduction in, frequency of drug administration, drug toxicity, drug fluctuation in blood, total drug usage, drug accumulation with chronic therapy, thus is economical to the health care providers and patients, improves patient compliance and often times eliminates the need for night dosing [11].

Commercial advantage includes, patent extension, product life-cycle extension, market expansion and product differentiation while disadvantages include, higher cost per unit dose, delayed onset of action, increase potential for first pass metabolism, possibility of less accurate dose adjustments in some cases, poor in vivo and in vitro correlation, possibility of dose dumping especially in the case of poor formulation strategy [12].

Sustained release system for oral solid formulations is, based on dissolution, diffusion or a combination of both mechanisms in the control of drug release. The rationale of such formulation involve, optimization of biopharmaceuticals, pharmacokinetic and pharmacodynamics of drug in a way, to maximize its utility through reduction of side effects, cure or control of condition in a shortest possible time and use of smallest amount of drug administered by suitable routes to achieve steady state blood or tissue level for an extended period. Two aspects most important to the drug delivery therefore involve spatial placement (targeting a drug to a specific organ or tissue) and temporal placement (controlling the rate of the drug delivery to target tissue) [13].

Various quality control tests carried out on pharmaceutical products such as tablets are as outlined Visual inspection, which observes, general appearance, size, shape, unique identification mark, labeling, organoleptic properties, and others.

Uniformity of weight used to determine the degree of weight consistency of formulated tablet where random selection and individual weighing of 20 tablets from each tablet batch using analytical weighing balance is involved [14].

Disintegration test involves study on extent of tablet break down, a requirement prior to dissolution. The tablet should pass stipulated disintegration test such as, within 15 minutes at $31+-0.5^{\circ} \mathrm{C}$ for immediate release tablets and for enteric coated tablets, should show no evidence of disintegration in simulated gastric fluid (SGF) after 1 hour but are expected to disintegrate within two hours in simulated intestinal fluid (SIF) [15].

56 | $\mathrm{P}$ a g e

www.iiste.org 
Uniformity of content as this helps to ensure that accurate amount of drug substance is contained in each tablet intended and with little variation among tablets within a batch. Drugs with low therapeutic index (active ingredient less than $2 \mathrm{mg}$ and or drugs with active ingredient less than $2 \%$ of total tablet weight requires the content uniformity test and assay is done on the tablets individually. The procedure involves the selection of twenty tablets randomly then assayed individually and the batch fails to comply when more than one tablet is outside the range of 85 to $115 \%$ of the average value or if any tablet is outside the range of 75 to $125 \%$ of the average [14].

Hardness test applied routinely to several tablet to ascertain extent of resistance to attrition or abrasion and crushing strength (axial or radial). The degree of the tablet hardness is dependent on its physical size or shape together with the characteristics of the formulation and the pressure applied in drug compression.

Friability test adopted as a measure to determine the loss of tablet weight due to abrasion or fracture. Dissolution studies involving choice of dissolution medium bearing in mind the nature of the drug substance and the sensitivity of the assay procedure. Two methods specified for USP dissolution test includes, rotating basket method very similar to the British pharmacopoeia and a paddle method in which the paddles present rotates in a bath of the dissolution fluid [16].

\section{Mechanism and Kinetics Of In Vitro Drug Release}

An ideal kinetic profile of drug release from a prolonged release carrier is a zero-order curve. The constant amount of an API dose within unit time provides the drug presence at a therapeutic level in human body during the long period. Most often, however Pharmaceutical products referred to as controlled release system (CRS) and composed of biodegradable polymeric matrix enclosing therapeutic agent reveal a complex heterogeneous release profile. The initial stage, called 'the burst effect', involves a rapid dissolution of part of drug not protected effectively by a carrier, then followed by slow release of drug fraction enclosed in matrix, induced by a polymer hydrolytic degradation [17].

A number of kinetic models describe the overall release of drug from the dosage forms since qualitative and quantitative changes in formulation may occur and alter drug release and in vivo performance. With this therefore, the need to develop tools that facilitate product development and reduce the necessity of bio-studies is desirable hence; in vitro drug dissolution data to predict in vivo bioperformance is considered, as the rational development of controlled release formulation.

Various approaches to investigating the kinetics of drug release from controlled release formulation are classified into, statistical (exploratory data analysis, repeated measures design, multivariate approach), model dependent methods (zero order, first order, Higuchi, Korsemeyer- Peppas model, Hixson Crowell, Baker-lonsdale model, Weibull model, etc) and model independent methods (differential factor $\left(f_{1}\right)$ and similarity $\left(f_{2}\right)[18]$.

Based on the model dependent methods therefore drug release kinetics can be analyzed as

Zero Order release usually independent on concentration and the release kinetics can be plotted using the formula

$\mathrm{Q}=\mathrm{Q}_{\mathrm{O}}+\mathrm{K}_{\mathrm{O}} \mathrm{t}$

Where $\mathrm{Q}$ is the amount of drug released or dissolved (assuming that release occurs rapidly after the drug dissolves), $\mathrm{Q}_{0}$ is the initial amount of drug in solution (usually zero), and $\mathrm{K}_{0}$ is the zero order release kinetics

First Order release often dependent on concentration and the kinetic is plotted using the relation

$\mathrm{dc} / \mathrm{dt}=\mathrm{k}\left(\mathrm{C}_{\mathrm{s}}-\mathrm{C}_{\mathrm{t}}\right)$

where $\mathrm{dc} / \mathrm{dt}$ is the rate of change in concentration with respect to time, and $\mathrm{k}$ is the rate constant. This is, simplified as

$\log C=\log C_{o}-k t / 2.303$

Here a plot could be, made between $\log C$ against time

Hixson-Crowell cube-root model involving the equation:

$\mathrm{Q}^{1 / 3}-\mathrm{Q}_{\mathrm{t}}{ }^{1 / 3}=\mathrm{K}_{\mathrm{HC}} \mathrm{t}^{\mathrm{C}}$

57 | P a g e

www.iiste.org 
$\mathrm{Q}_{\mathrm{t}}$ is the amount of drug released in time $\mathrm{t}, \mathrm{Q}_{\mathrm{o}}$ is the initial amount of drug in tablet and $\mathrm{K}_{\mathrm{HC}}$ is the rate constant for Hixson - Crowell rate equation and a plot could be made between cube root of drug \% remaining in matrix verse time.

Higuchi model involving the relation

$\log \mathrm{Q}=\log \mathrm{KH}+1 / 2 \log \mathrm{t}$

Where $\mathrm{Q}$ is the amount of drug released in time t per unit area, $\mathrm{C}$ is the initial drug concentration, $\mathrm{C}_{\mathrm{s}}$ is the drug solubility in the matrix media and $\mathrm{KH}$ is Higuchi dissolution constant. Here a plot is made between $\log Q$ versus $1 / 2 \log t$

Korsmeyer-peppas model, which involves the relation

$\mathrm{M}_{\mathrm{t} /} / \mathrm{M}_{\infty}=\mathrm{Kt}^{\mathrm{n}}$

where $M_{t} / M_{\infty}$ is fraction of drug released at time $t, k$ is the rate constant and $n$ is the release exponent. The $\mathrm{n}$ value in this model is, used to characterize different release mechanisms and a plot is, made between $\log \mathrm{M}_{\mathrm{t}} / \mathrm{M}_{\alpha}$ against $\log$ time.

\section{Significance of Study}

To determine and compare the properties of commercially marketed sustained release tablets of diclofenac sodium and investigate the in-vitro release mechanism and dissolution profiles of some brands of the tablets sold in Port Harcourt metropolis, south-south, Nigeria, in order to assess their efficacy and proffer suggestions on their interchangeability.

\section{Materials and Methods}

\section{Materials}

Brands of diclofenac sodium tablets such as: voltaren, betaren Dexel, diclogen, lofnac, clofenac. (retail Pharmacies in Port Harcourt, Rivers State, Nigeria). Pure sample of diclofenac sodium and trisodium phosphate buffer (purchased in Onitsha, Anambra state Nigeria), sensitive weighing balance, tablet hardness tester (Mosanto, England), friabilator (Erweka, Germany) dissolution unit (Erweka 600,Germany), disintegration unit(Erweka D63150,Germany), UV-Vis spectrophotometer ( 6450UV, Jenway England), pH meter (Jenway, England).

\section{Methods}

Identification and Confirmatory Test for Diclofenac Sodium

A $60 \mathrm{mg}$ of the pure diclofenac powder was dissolved in $0.5 \mathrm{ml}$ of methanol and $0.5 \mathrm{ml}$ of water and the solution was observed for reaction of sodium.

A clean and moistened flame test wire was dipped into a powder sample and put into the edge of a blue flame ignited with bunsen burner.

\section{Weight Uniformity Test}

Twenty (20) tablets were selected from each of the brands. The tablet was weighed together using sensitive electronic weighing balance. Their average weight was calculated and the equation weight variation determined following the equation below Highest weight Variation $=\frac{\text { Highest weight } \text {-Average weight }}{\text { Average Weight }} \times 100$

Lowest weight variation $=\underline{\text { Lowest weight }- \text { average weight }} \times 100$

$$
\text { Average weight }
$$

Hardness Test

The crushing strengths of ten tablets selected from each brand were determined using Mosanto hardness tester. 


\section{Friability Test}

Ten (10) tablets were selected from each brand, with initial weight (Wo ) and placed in the Erweka friabilator set at $25 \mathrm{rpm}$ for $4 \mathrm{mins}$. After 4 minutes at 100 revolutions per minute (rpm), the tablets were collected, dusted and reweighed. The final weight (W) was determined and the friability was then calculated using the formula.

$$
\% \text { Friability }=\underline{W_{0}} \frac{-W}{W_{0}} \times 100
$$

\section{Preparation of Phosphate Buffer of pH 6.8 as dissolution medium.}

A $76 \mathrm{~g}$ of tribasic sodium phosphate was weighed and dissolved in water to obtain $1000 \mathrm{ml}$ of solution. $250 \mathrm{ml}$ of the solution was mixed with $750 \mathrm{ml}$ of $0.1 \mathrm{~N}$ hydrochloric acid and the $\mathrm{pH}$ was adjusted to 6.8 (USP).

\section{Preparation of 0.1N HCL}

An $8.4 \mathrm{ml}$ of concentrated HCL was carefully measured in a fume cupboard, thereafter transferred into a $1000 \mathrm{ml}$ measuring cylinder containing $250 \mathrm{ml}$ of distilled water, and then made up to $1000 \mathrm{ml}$.

\section{Disintegration Test}

The disintegration time of 6 tablets selected from each batch was determined using a disintegration medium containing phosphate buffer of $\mathrm{pH} 6.8$ maintained at $37 \pm 0.5^{\circ} \mathrm{C}$. The mean disintegration time was then calculated.

\section{Preparation of Standard Calibration Curve}

A $50 \mathrm{ml}$ solution of $50 \mathrm{mg}$ diclofenac sodium powder was prepared using a phosphate buffer $\mathrm{pH} 6.8$ to obtain a stock solution containing $1 \mathrm{mg} / \mathrm{ml}$. Serial dilutions were made to obtain solutions of $0.02 \mathrm{mg} / \mathrm{ml}, 0.04 \mathrm{mg} / \mathrm{ml}, 0.06 \mathrm{mg} / \mathrm{ml}, 0.08 \mathrm{mg} / \mathrm{ml}, 0.10 \mathrm{mg} / \mathrm{ml}$ and $0.12 \mathrm{mg} / \mathrm{ml}$. The absorbance of were determined using UV-spectrophotometer at wavelength of $\lambda_{\max } 250 \mathrm{~nm}$ and a graph of absorption against concentration plotted.

\section{Content of Active Ingredient}

Twenty(20) tablets of each brand were weighed collectively and crushed. The average weight obtained was dissolved in $100 \mathrm{ml}$ of freshly prepared phosphate buffer of $\mathrm{pH} 6.8$ to extract for 30mins and filtered. The solutions obtained were scanned in the UV spectrophotometer at absorption wavelength of $\lambda_{\max } 250 \mathrm{~nm}$ and the content of diclofenac sodium was determined.

\section{Dissolution Test}

$900 \mathrm{~mL}$ volume of freshly prepared dissolution medium $(\mathrm{pH} 6.8$ phosphate buffer) was transferred into the dissolution jars and maintained at $37 \pm 0.5^{\circ} \mathrm{C}$. The paddles were made to rotate at 100rpm. One tablet from each batch was placed in the dissolution media and $5 \mathrm{ml}$ of sample was withdrawn and replaced with equal volume of fresh media at intervals of $1 \mathrm{hr}, 2 \mathrm{hrs}, 3 \mathrm{hrs}, 4 \mathrm{hrs}, 5 \mathrm{hrs}$,and $6 \mathrm{hrs}$. The withdrawn sample solution was then filtered and analyzed in UV spectrophotometer at absorbance wavelength of $\lambda_{\max } 250 \mathrm{~nm}$ after which the percentage (\%) of drug release was calculated.

\section{Data Analysis}

Descriptive statistical analysis was done using 2007 microsoft excel to determine the mean and standard deviations. Also statistical analysis using model independent methods such as: similarity factor $\left(\mathrm{f}_{2}\right)$, involving the following equation was used:

$$
\mathrm{f}_{2}=50 \log \left\{\left[1+\left(\frac{1}{n}\right)\right] \Sigma_{t=1}\left[\left(\mathrm{R}_{t}-\mathrm{T}_{t}\right)^{2}\right]^{-0.5} \cdot 100\right\}
$$

where $f_{2=}$ Similarity and $f_{2}$ values of $50-100$ shows similarity $\mathrm{n}=$ number of time points or samplings, $\mathrm{R}_{\mathrm{t}}=$ Cumulative percentage drug release at time $(\mathrm{t})$ of reference brand, $T_{t}=$ Cumulative percentage drug release at time $(t)$ of test brand

\section{9 | P a g e}


International Journal of Scientific and Technological Research

ISSN 2422-8702 (Online), DOI: 10.7176/JSTR/7-02-06

Vol.7, No.2, 2021

Results

Confirmatory test of diclofenac sodium powder: A yellow flame was produced indicating the presence of sodium.

Table1: Description of Six Brands of Sustained Release Diclofenac Sodium Tablets.

\begin{tabular}{|cccccccc|}
\hline $\begin{array}{c}\text { Brand } \\
\text { code }\end{array}$ & $\begin{array}{c}\text { Brand } \\
\text { name }\end{array}$ & $\begin{array}{c}\text { Strength } \\
(\mathrm{mg})\end{array}$ & Batch no & Mfg date & Exp date & $\begin{array}{c}\text { Nafdac } \\
\text { Reg no }\end{array}$ & $\begin{array}{c}\text { Country of } \\
\text { manufacture }\end{array}$ \\
\hline A & Nemel & 100 & $02 \mathrm{k}$ & $11-2016$ & $10-2021$ & B4-1204 & Nigeria \\
\hline B & Lofnac & 100 & DLT 147 & $02-2019$ & $01-2022$ & $04-7290$ & India \\
\hline C & Clofenac & 100 & BJ0718 & $04-2018$ & $03-2021$ & $04-3873$ & Malaysia \\
\hline D & Voltaren & 100 & SHA24 & $04-2018$ & $03-2023$ & & Turkey \\
\hline E & Diclogen & 100 & 170705 & $07-2017$ & $07-2020$ & B4-1204 & China \\
\hline F & $\begin{array}{c}\text { Betaren } \\
\text { Dexel }\end{array}$ & 100 & 1812059 & $12-2018$ & $12-2023$ & $04-3877$ & Israel \\
\hline
\end{tabular}

Table 2: Organoleptic Test

\begin{tabular}{|l|l|l|l|l|l|l|}
\hline Test & Batch A & Batch B & Batch C & Batch D & Batch E & Batch F \\
\hline Colour & $\begin{array}{l}\text { Light } \\
\text { orange }\end{array}$ & $\begin{array}{l}\text { Dark } \\
\text { orange }\end{array}$ & Pink & & Salmon & Light salmon \\
\hline Shape & Circle & Circle & Circle & Circle & Circle & Circle \\
\hline Texture & Smooth & smooth & Smooth & Smooth & Smooth & Smooth \\
\hline Aroma & Pleasant & Pleasant & pleasant & Pleasant & pleasant & Pleasant \\
\hline Scoring & Present & Present & present & Absent & Absent & Absent \\
\hline Inscription & Present & Present & Present & Present & Present & Present \\
\hline Taste & Tasteless & Sour & Tasteless & Tasteless & Tasteless & Tasteless \\
\hline
\end{tabular}

Table 3: Weight uniformity

\begin{tabular}{|c|c|c|c|}
\hline \multirow{2}{*}{ BRAND CODE } & $\begin{array}{c}\text { MEAN } \\
\text { WEIGHT(M) } \\
\text { STANDARD } \\
\text { DEVIATION }\end{array}$ & $\begin{array}{c}\text { \% VARIANCE } \\
\text { (USP } \pm \text { \%10) }\end{array}$ & REMARK \\
\hline A & $425.63 \pm 0.025$ & $\mathbf{5 . 9 4 4}$ & Passed \\
\hline B & $\mathbf{3 6 9 . 9 7} \pm \mathbf{0 . 0 0 5}$ & $\mathbf{1 . 6 0 4}$ & Passed \\
\hline C & $\mathbf{3 6 9 . 9 7} \pm \mathbf{0 . 0 0 5}$ & $\mathbf{2 . 6 5 6 6}$ & Passed \\
\hline D & $300.45 \pm \mathbf{0 . 0 0 3}$ & $\mathbf{1 . 2 6 1 0}$ & Passed \\
\hline E & $296.47 \pm 0.003$ & 1.3187 & Passed \\
\hline F & $\mathbf{3 0 9 . 4 5} \pm \mathbf{0 . 0 0 1}$ & $\mathbf{0 . 6 4 0 9}$ & Passed \\
\hline
\end{tabular}

$60 \mid \mathrm{P}$ a g e

www.iiste.org 
Table 4: Result of Hardness, Friability and Disintegration time

\begin{tabular}{|l|c|c|c|}
\hline Brand code & $\begin{array}{c}\text { Crushing strength(kgf) } \\
\pm \text { SD }\end{array}$ & \%Friability & $\begin{array}{c}\text { Mean } \\
\text { Disintegration } \\
\text { time } \pm \text { SD (mins) }\end{array}$ \\
\hline A & $9.51 \pm 1.13$ & 9.87 & $67.5 \pm 5.04$ \\
\hline B & $5.42 \pm 0.48$ & 0.02 & $17.01 \pm 0.46$ \\
\hline C & $8.3 \pm 0.25$ & 0.02 & $\begin{array}{c}\text { Did not } \\
\text { disintegrate after } \\
3 \text { hours }\end{array}$ \\
\hline D & $7.55 \pm 0.15$ & -0.07 & $61.56 \pm 2.32$ \\
\hline E & $6.85 \pm 0.41$ & -0.05 & $19.15 \pm 8.09$ \\
\hline F & $4.00 \pm 1.11$ & -0.15 & $84.33 \pm 9.85$ \\
\hline
\end{tabular}

Table 5: Content of Active Ingredient

\begin{tabular}{|l|c|c|c|}
\hline Brand code & $\begin{array}{c}\text { Amount of } \\
\text { drug(mg) }\end{array}$ & \% content & Remark \\
\hline A & 80.08 & 80 & Passed \\
\hline B & 98.74 & 98.7 & Passed \\
\hline C & 126.95 & 126.9 & Failed \\
\hline D & 99.65 & $99^{\prime} 6$ & Passed \\
\hline E & 109.21 & 109.2 & Passed \\
\hline F & 91.46 & 91.4 & Passed \\
\hline
\end{tabular}

Table 6: Correlation Coefficients of Zero Order, Higuchi and Korsmeyer-Peppas Release Kinetics of Diclofenac Sodium

\begin{tabular}{|l|l|l|l|l|l|}
\cline { 4 - 6 } \multicolumn{2}{c|}{} & \multicolumn{3}{c|}{ Korsmeyer-Peppas kinetics Model } \\
\hline Batch code & $\begin{array}{c}\mathrm{R}^{2} \text { value } \\
\text { of } \\
\text { Zero Order }\end{array}$ & $\begin{array}{c}\mathrm{R}^{2} \text { value of } \\
\text { Higuchi } \\
\text { model }\end{array}$ & $\begin{array}{c}\mathrm{R}^{2} \\
\text { value }\end{array}$ & $\begin{array}{c}\text { Release } \\
\text { Exponents(n) } \\
\text { of test brands }\end{array}$ & Release mechanism \\
\hline A & -1.48 & -0.272 & 0.6084 & 0.2 & Anomalous \\
\hline B & 0.8148 & 0.7886 & 0.517 & 0.615 & Fickian diffusion \\
\hline C & -1.504 & 0.3178 & 0.154 & 0.1593 & Anomalous \\
\hline D & -0.54 & -0.285 & 0.667 & 0.2048 & Anomalous \\
\hline E & 0.7939 & 0.9577 & 0.9063 & 0.5268 & Fickian diffusion \\
\hline F & 0.7597 & 0.9417 & 0.9405 & 0.5288 & Fickian diffusion \\
\hline
\end{tabular}




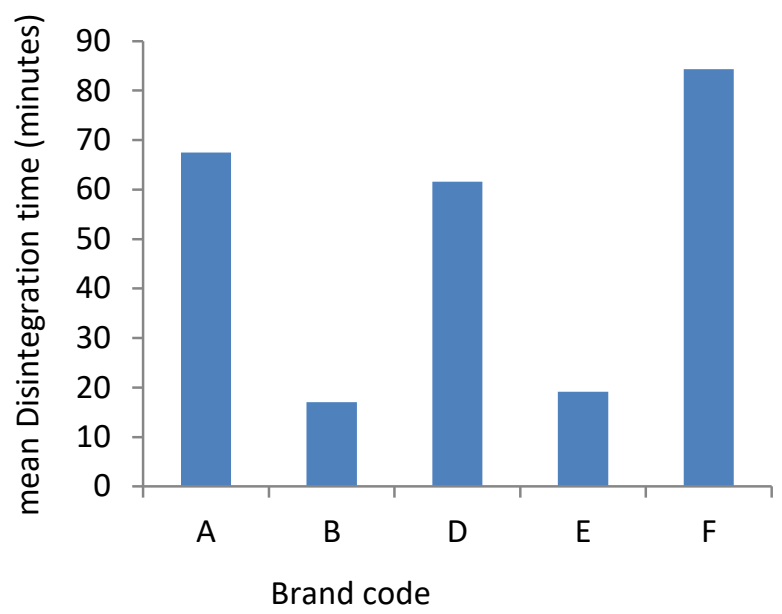

Fig 1: Disintegration Time Test

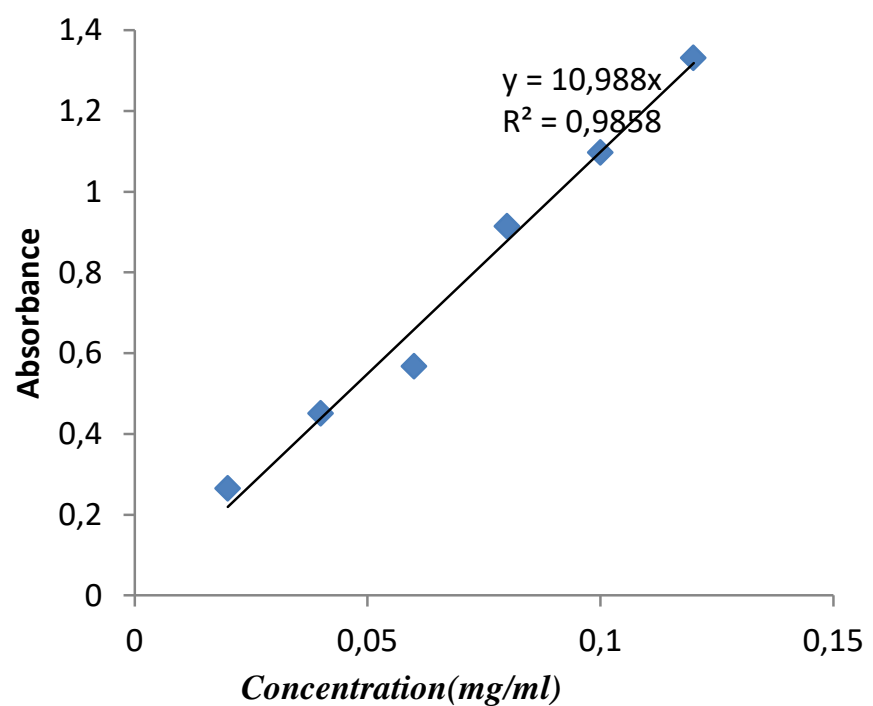

Figure 2: Calibration curve plot of diclofenac sodium

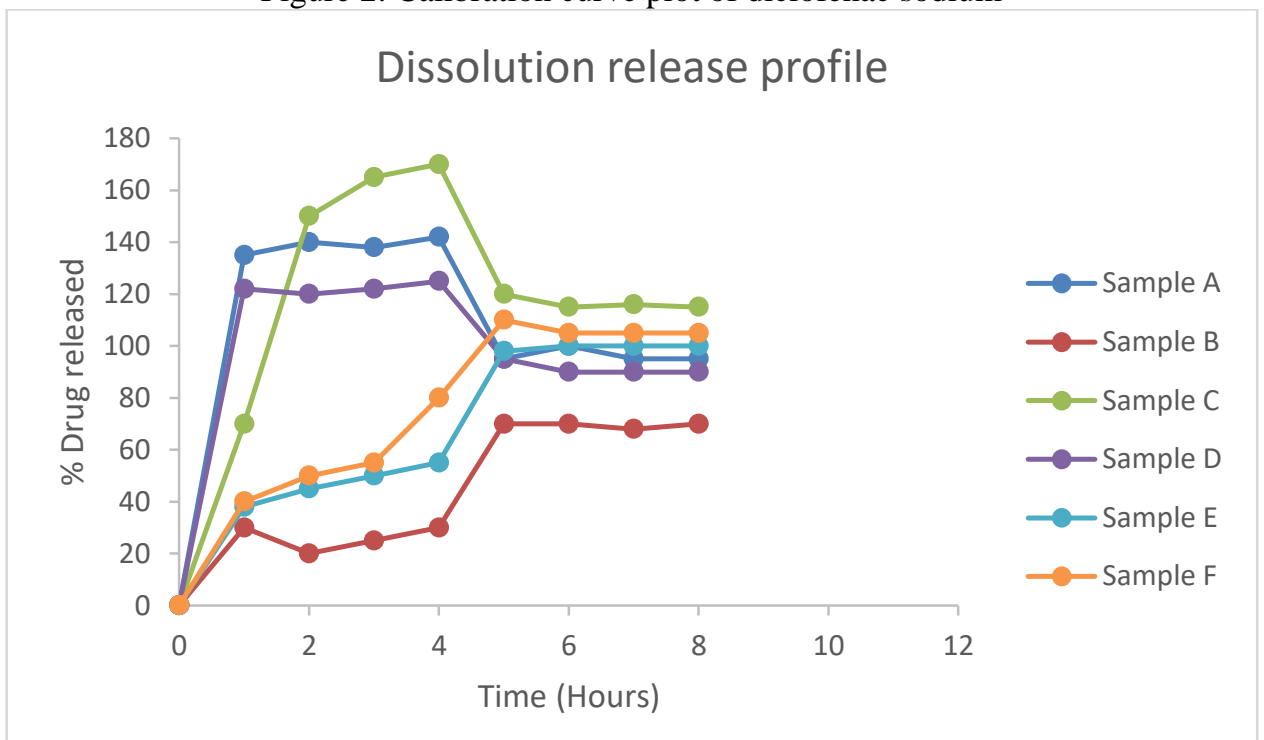

Figure 3: Release profile for the six brands of sustained release diclofenac sodium tablets. 


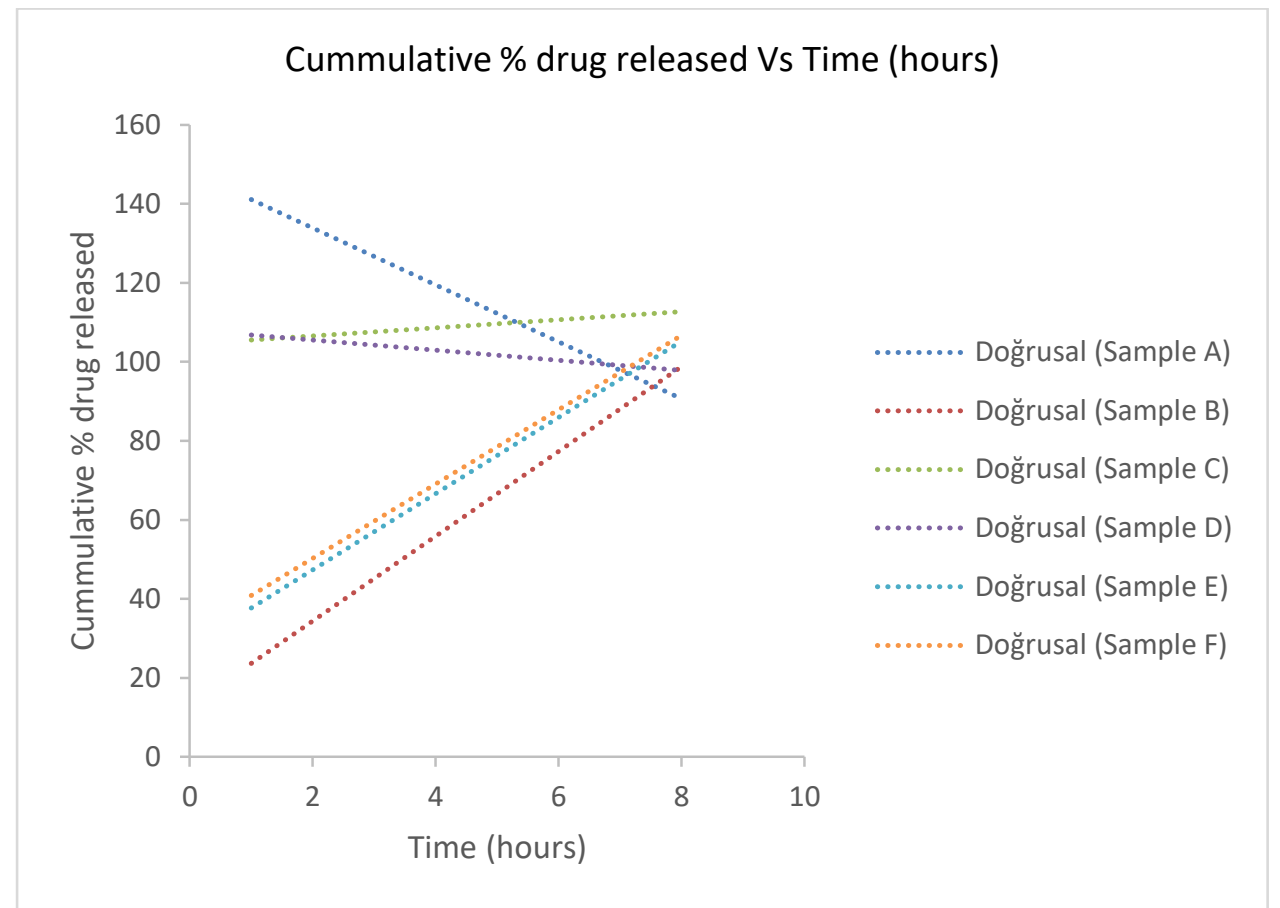

Fig4: Zero order plot of cumulative \% drug released against time (hours) for diclofenac tablets

Higuchi Model Kinetics

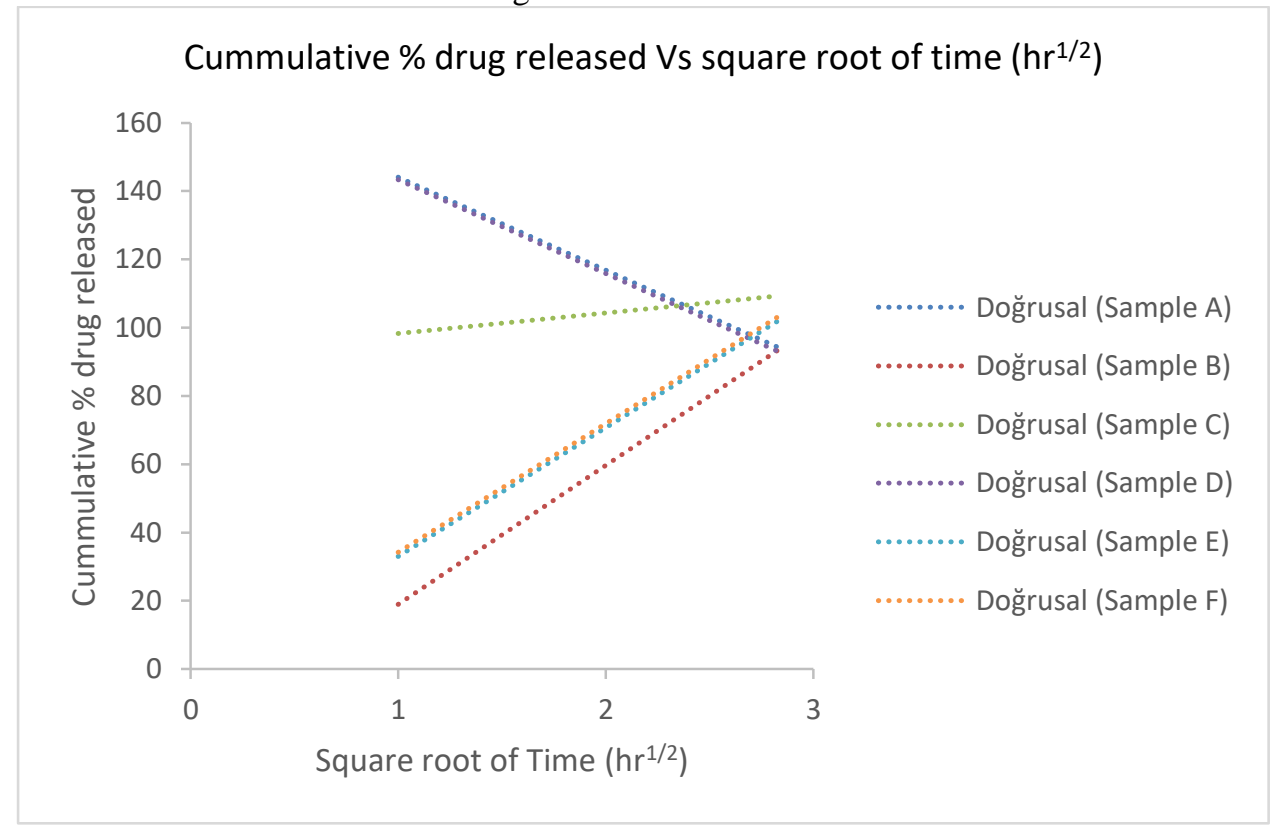

Fig 5: Higuchi Plot of the Release Profile of Diclofenac Sodium from Batches A to F 


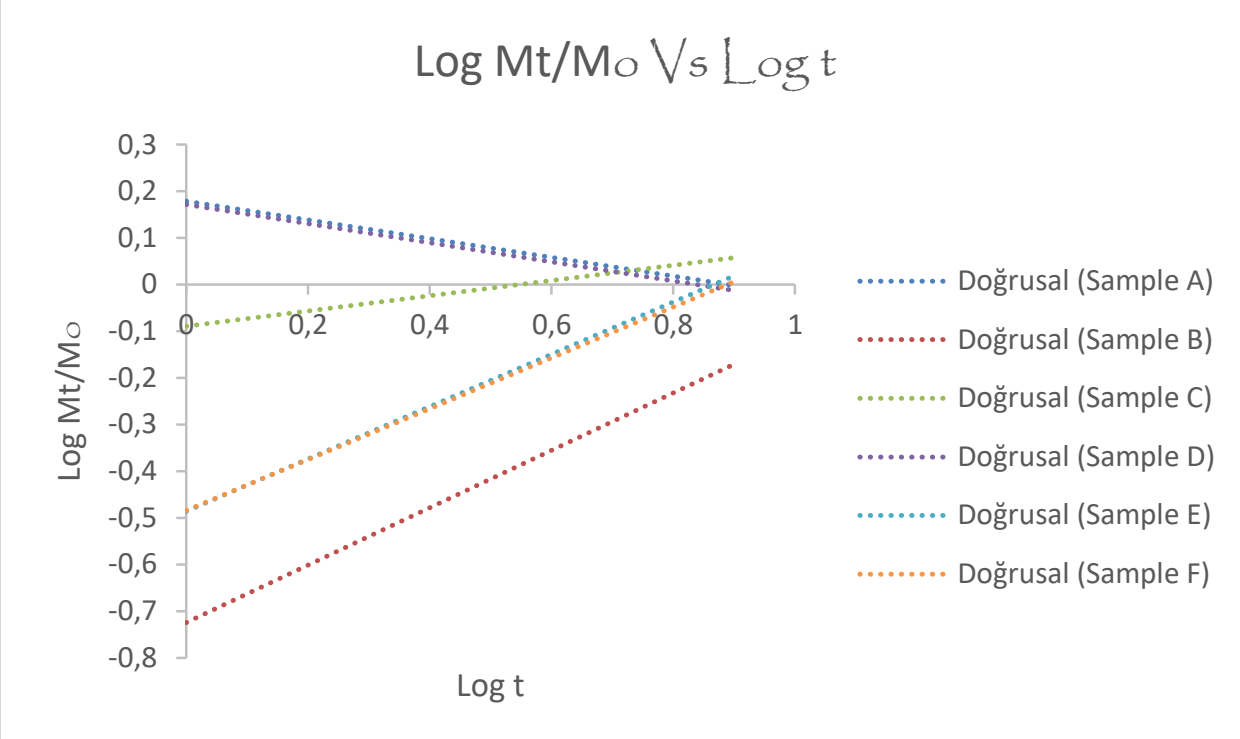

Fig6: korsmeyer-peppas plot of the release profile of diclofenac sodium batches A to F

\section{Discussion}

Weight uniformity is an indication of the amount of active pharmaceutical ingredient (API) in the tablet but it is not a guarantee of API uniformity in all the tablets. The variation in weight of individual tablets indicates a corresponding variation in the drug content and from the results obtained, none of the tablets had a deviation of more than $+/-5 \%$ and this implies that the tablets comforms with the results of the weight uniformity test carried out.

The hardness or crushing strength measures the force required to break a tablet and the mechanical strength of a tablet determines its disintegration time and dissolution rate. In order to withstand chipping, abrasion, and or breakage, which may occur during transportation, storage and handling, tablets are required to have a certain degree of hardness. At a constant die fill, the crushing strength values increases as additional compression force is applied [19].The harder a tablet is, the less friable and more time it takes to disintegrate. A force not less than 4 to $8 \mathrm{kgF}$ is accepted as satisfactory for tablet hardness (B.P 2004). All the batches of the diclofenac sodium tablets had hardness values higher than $4 \mathrm{kgF}$ as shown in table 4 . From the results obtained, it was observed that batch $\mathrm{F}$ required the least pressure before fracture (with average hardness of $4 \mathrm{kgF}$ ), but batch A tablets had the highest hardness values (with average of $9.51 \mathrm{kgF}$ ) hence the tablets of all the batches complied with the BP specifications.

Friability test evaluates the tablets resistance to abrasion and the USP specifies that the value should not exceed 1\% (USP 2005, BP 2009). Friability for all the batches was less than 1\% except for batch A (with value of $9.51 \%$ ) as seen in table 4. This implies that all the batches complied with the pharmacopoeia specification except batch A which is most likely to lose particles during handling while batch D is the least likely to lose particles.

Content uniformity assay determines the concentration of the API, in a tablet and according to the BP, the concentration of diclofenac sodium is accepted if it is within the range of $90-110 \%$. From the results obtained, all the brands assayed have their diclofenac sodium content within this range except batch C (with concentration of 126\%). Thus, all the batches except batch $\mathrm{C}$ complied with pharmacopoeia specification for content of active ingredient.

Dissolution test measures the concentration of the drug product in a given medium at a specified time. The result analyzed, was, interpreted using Beer-Lambert's plot as shown in fig 2. The in vitro drug release profiles of batches A-F tablets are as shown in fig 3 and all the batches maintained, a sustained release of diclofenac sodium up to 8hours though with variations on rate and extent of release.

Considering, the drug release mechanism, kinetics and similarities of, batch A-F of the diclofenac sodium tablets, batch A, C and D was, observed to have anomalous release kinetic profile, batch B was, dominated by Zero order release while batch $\mathrm{E}$ and $\mathrm{F}$ followed, Higuchi diffusion model though, with 
signs of zero order kinetics because of the $\mathrm{R}^{2}$ value obtained. The $\mathrm{R}^{2}$ value was greater than 0.5 hence closer to unity and the more the value is to unity the greater zero order dominance.

This multiple release kinetics could co-exist because of influence of individual particle lattice structure and composition, which make the labelled matrix a heterogeneous system. Therefore, the Higuchi kinetic model may show dominance but the other kinetic of drug release may still be in operation at minimal levels. Korsmeyer - Peppas revealed that batches B, E and F had Fickian transport mechanism of drug release but the drug release mechanism for batch A, C and D were anomalous. All the batches analyzed suitably sustained the release of diclofenac sodium up to 8hours though batches $\mathrm{F}$ and $\mathrm{E}$ could be preferably be used interchangeably or as pharmaceutical alternatives based on their similarity factor of value 50.03 and were also observed to have same Fickian diffusion drug release mechanism as obtained with korsmeyer-peppas drug release profile.

\section{Conclusion}

Based on the assay carried out on the various diclofenac sodium samples it could be affirmed that all tested brand suitably sustained the release of active component for up to 8hours though with variations in rate and extent.

From the outcome of the study, batch $\mathrm{E}$ and $\mathrm{F}$ were observed to have similarity factor of a value 50.03 hence could be recommended to be used interchangeably or as pharmaceutical alternatives more so as they were also observed to release their active component through same process of Fickian diffusion method.

\section{References}

1. Roy Altman, Bill Bosch, Kay Brune, Paola Patrignani, and Clarence Young. 2015; Advances in NSAID Development: Evolution of Diclofenac Products Using Pharmaceutical Technology. Spriger-Drugs; 75(8): 859-877. doi: 10.1007/s40265-015-0392-,

2. Adamo Fini, Cristina Cavallari, Glenda Bassini, Francesca Ospitali, Rita Morigi 2012; Diclofenac salts, part 7: Are the pharmaceutical salts with aliphatic amines stable? Journal of pharmaceutical Sciences; https://doi.org/10.1002/jps.23052

3. Alfred R. Sallmann, Ph.D. 1986; The history of Diclofenac. The American journal of medicine; volume 80, issue 4, supplement 2, 29-33, doi:https://doi.org/10.1016/0002- 9343(86)90076-

4. Tong J Gan 1. 2010; Diclofenac: An Update on Its Mechanism of Action and Safety Profile. Curr med opin. 2010;26(7):1715-31. doi: 10.1185/03007995.2010.486301.

5. C. E. Wilson, A. P. Dickie, K. Schreiter, R. Wehr, E. M. Wilson, J. Bial, N. Scheer, I. D.Wilson \& R. J. Riley. 2018; The pharmacokinetics and metabolism of diclofenac in chimeric humanized and murinized FRG; 92, 1953-1967.

6. Diclofenac Side Effects. Medically reviewed by Drugs.com. Last updated on Jan 20, 2020Diclofenac: New contraindications and warnings. New recommendations after a Europewide review of cardiovascular safety.Published 11 December 2014. From: Medicines and Healthcare products Regulatory Agency.

7. Gendre C., Genty M., César da Silva J., Tfayli A., Boiret M., Lecoq O., Baron M., Chaminade P., Péan J-M., Comprehensive study of dynamic curing effect on tablet coating structure, Eur. J. Pharm. Biopharm., 81 (2012), 657-665

8. James A. Seitz, Gerald M. Flessland. 1965; Evaluation of the physical properties of compressed tablets I. Tablet hardness and friability. Journal of pharmaceutical sciences. https://doi.org/10.1002/jps.2600540926 
9. K. J. Wadher,* R. B. Kakde,1 and M. J. Umekar. 2011; Formulation and Evaluation of a Sustained-Release Tablets of Metformin Hydrochloride Using Hydrophilic Synthetic and Hydrophobic Natural Polymers. Indian journal of pharmaceutical science; 73(2):208-215. Doi. $10.4103 / 0250-474 \times 91579$.

10. Ivo Elliott, Mayfong Mayxay, Sengchanh Yeuichaixong, Sue Lee and Paul Newton; 2014; The practice and clinical implications of tablet splitting in international health. Tropical Medicine \& International Health;19(7):754-760,DOI: 10.1111/tmi.12309

11. Anindya Ghose, Sang Pil Han and Kaiquan Xu . Mobile commerce in the new tablet economy completed research paper. Thirty fourth international conference on information systems. Milan 2018 Pg1-18.

12. Gujral G, Kapoor D, Jaimini M. 2018; An updated review on modified release tablets, Journal of Drug Delivery and Therapeutics; 8(4):5-9 DOI: http://dx.doi.org/10.22270/jddt.v8i4.1722

13. N Katori 1, N Aoyagi, S Kojima. 2001; The Study of the Applicability of Content Uniformity and Weight Variation Test--The State of Commercial Tablets and Capsules in Japan. Chem pharm Bull(Tokyo); 49(11):1412-9. doi: 10.1248/cpb.49.1412.

14. Daniel Mark and J. Axel Zeitler. 2017; A Review of Disintegration Mechanisms and Measurement Techniques.Journal of pharm Resource; 34(5): 890-917. doi: 10.1007/s11095$017-2129-\mathrm{z}$

15. Costa P, Lobo JMS . 2001; Influence of dissolution medium agitation on release profiles of sustained release tablets. Drug Devel Ind Pharm 27 (8), 811-817.

16. Chime Salome Amarachi, Godswill Onunkwo and Ikechukwu Onyishi . 2013; Kinetics and mechanisms of drug release from swellable and non swellable matrices: A review.Research Journal of Pharmaceutical, Biological and Chemical Sciences 4(2):97-103.

17. Apurba Sarker Apu1*, Atiqul Haque Pathan1, Dilasha Shrestha, Golam Kibria and Reza-ul Jali12. 2009; Investigation of In vitro Release Kinetics of Carbamazepine from Eudragit ${ }^{\circ}$ RS PO and RL PO Matrix Tablets. Tropical Journal of Pharmaceutical Research; Vol. 8,(2): 145152 ISSN: 1596-5996 EISSN: 1596-9827

18. Chamroeun Chhorn, Seong JaeHong and Seung WooLee. 2018; Relationship between compressive and tensile strengths of roller-compacted concrete. Journal of Traffic and Transportation Engineering(English edition); 5(3):215-223 